\title{
5
}

\section{Benchmarking-The neglected element in total quality management}

\author{
F.W. Swift ${ }^{\mathrm{a}}$, T. Gallwey ${ }^{\mathrm{b}}$, and J.A. Swift ${ }^{\mathrm{c}}$ \\ ${ }^{a}$ Mechanical Engineering, Florida International University \\ University Park, Miami, Florida, USA \\ ${ }^{\mathrm{b}}$ Production and Operations Engineering, University of Limerick, Limerick Ireland \\ ${ }^{\mathrm{c} I n d u s t r i a l}$ Engineering, University of Miami, Miami, Fl. USA
}

\section{EVOLUTION OF TOTAL QUALITY MANAGEMENT (TQM)}

Long before the twentieth century, merchants and craftsman knew the importance of quality. While the term meant different things to different people, it was valued to be an important, intangible commodity. The concept of specifications, inspection with respect to these specifications and later, the refined aspects of measurements with respect to the field of metrology, has been with us for many years. With the coming of the twentieth century and especially with the advent of the industrial revolution, quality, in many different forms and different names, became the criterion to be "championed". The earliest serious works centered around "quality control" and perhaps quality planning. In the early stages, the emphasis was on inspection, and inferior products (non-conforming products) were reworked or discarded as scrap. The literature is replete with historical and evolutionary quality efforts which were not economically acceptable, and these will not be duplicated here.

What is enlightening, is the fact that the whole field and concept of quality began to change in the late 1940's after World War II. The real explosion of "new" definitions and concepts did not emerge until the 1980's. This revolution is continuing today and will continue to cause change for at least another 10 years.

Of vital importance to this research and this paper, is the changing mosaic which now makes up quality, and TQM's place in society. While some still deny the value and even the existence of its importance, TQM continues to dominate the free market systems in the world today.

Following the lead of the Japanese, as tutored by Dr. Deming, four important elements evolved which revolutionized quality in the market place. First, he tutored upper management to make a commitment to quality and insure that quality was emphasized throughout the organization. Second, all levels and all functions were to receive quality training at some specified level of expertise. Third, quality improvement was to be a continuous process as later defined by the Deming wheel. And finally, the customer was to be the most important concern in the "quality loop". There are many reasons why this has prevailed, and even today the customer is very cognizant of quality and value. Most consumers are more educated in quality, and everyone 
seems to demand it. But, the battle cry today is "quality at a reasonable cost" instead of quality at any cost. Since many accepted definitions of quality today include a clause or phrase "quality is customer satisfaction", this new concern will receive attention by those who expect to make a reputation by catering to the sophisticated customer.

One difficulty encountered today is the concern related to environmental issues, ergonomics aspects and health and safety concerns. These and other related issues are not normally of a direct concern to the consumer, and therefore not requested by the customer. However, they must be included and they do add incrementally to total cost. Addressing these issues takes a unique manager who can properly balance these concerns while still providing customer wants.

\section{HISTORICAL PERSPECTIVE OF BENCHMARKING}

Interestingly enough, quality, in its earlier history was at times called benchmarking, or more precisely, benchmarking was called "product quality and feature comparisons". (Camp, p.6) This could account for the similarities and common elements in these two management tools. Even the historical development has some common elements, as seen in this paper.

Since 1979, the concept of benchmarking has taken on radical new meanings. Before that time, benchmarking simply meant comparing various components of the company to the previous year's performance. In the earliest uses of benchmarking, the definition of Webster was sufficient. "...A surveyor's mark...of previously determined position...and used as a reference point." A company would simply decide which measures of performance to follow, and measure themselves from year to year. The most common measures were related to economic parameters. They included profits, sales volume, expenses, some type of performance ratio or some other parameter. Strategic planners would opt for some percentage increase or decrease. If this goal was met or exceeded, then the unit was declared a success for the period in question.

Most researchers and writers suggest that 1979 was the emerging point of benchmarking as a vital management tool. Xerox is given credit for first discovering that it would become vital to use benchmarks to compare itself to other competitors as well as to reference points within their own organization. At that time, Xerox's manufacturing unit decided to compare unit manufacturing costs and features of their copying machines to those of competitor machines. Thus began the concept. While there has been a slow but steady increase in the use of benchmarking, it has been growing rapidly in importance. When one recognizes the value and importance of competitive benchmarking, it is easy to understand the virtual explosion of its use.

Improvement goals based solely on the company's own past performance are no longer sufficient. In fact the definition itself has undergone a revolution. In 1979, Xerox realized that the old Webster definition was no longer sufficient and adopted a new one: 
"The continuous process of measuring our products, services, and business practices against the toughest competitors or those companies recognized as industry leaders."

D.T.Kearns, Xerox CEO (Camp, p. 10)

It will be noted by those who work extensively in TQM that this definition has strong similarities with the now currently accepted definitions of quality and quality improvement. There are many other definitions that have evolved, but this paper is not intended as an extensive development of benchmarking. It is intended to show that there is a high correlation between the work being done in TQM and the work being done in benchmarking. There is an inherent synergism which needs to be developed. A systematic development for a common model will advance this management tool to make companies competitive on a world scale.

A Chinese proverb which is attributed to a Chinese general over 2000 years ago states, "If you know your enemy and know yourself, you need not fear the results of a hundred battles". (Tzu, p 84) This proverb (whether true or mythical), can be paraphrased here and used as sound advice for managers. If you know your own product and your own company well enough, you need not fear competition from other companies. It has become a truism that one must study and know more about all aspects of one's company, because in this modern age at the dawn of the 21 st century, "knowledge is power".

Benchmarking will become more useful especially in the all important aspect of quality. It will be important to be competitive with the "best of the best" and it needs to be understood that this is a dynamic and continuous process.

\section{COMMON ELEMENTS}

As noted in the last two sections, there are commonalities in the two management techniques. In all the current definitions for benchmarking and TQM, there are references to: continuous-systematic improvement, meeting customer requirements, performance standards, striving for the best of the best, understanding industries' best practices regardless of the product or service, and many other elements. It is also noted that, the definitions associated with quality and TQM have taken significant, and parallel development with benchmarking concepts since the 1970's.

In the earliest days, conformance to specifications and inspection of final products was considered very important. This began the meaning of quality. Early in the twentieth century, formal definition was given to this concept, and significant importance was given to meeting prescribed specifications as a means of obtaining quality. It was not until the work of Deming, Juran, and Ishikawa in the 1950's and 1960's that the current meaning of quality, and Total Quality Management began to emerge.

With Dr. Deming's concept of continuous improvement using the familiar PDCA continuous improvement wheel, and his success in Japan after World War II; the tremendous focus on customer needs and satisfaction; Dr. Juran's recognition of the Pareto principle and its application to quality problems; we find a great amount of commonality between the ideals of 
benchmarking and quality improvement. In Quality Planning and Analysis, Drs. Juran and Gryna recognize that competitive analysis is one of the distinguishing features of modern strategic quality management, but they did not emphasize the power of benchmarking functions from dis-similar companies.

A close review of all the writings on benchmarking since 1988 and a review of writing and analysis on total quality management will reveal a closer link than previously realized. Yet, when one studies the criteria for the most prestigious awards, and the criteria for quality certification (ISO 9000), it is curious to note that very little mention is given to benchmarking.

It seems that this omission should be rectified by making an extensive study of the relative merits of benchmarking, and its value to a company's quality efforts, as compared to other topics in the criteria for quality awards and ISO 9000 certification. It will be beneficial to note some specifics especially in the certification criteria.

Of all the certifying criteria, probably the best known and the most widely accepted is the ISO 9000 certifications. A review of the most up-to-date criteria for 9001,9002 and 9003 would seem to indicate that benchmarking is not essential to receiving certification. While there are sections that relate to the goals of benchmarking, there are no specific criteria that requires that any sort of benchmarking be done.

The three quality awards which have the most prestige today are the Deming Application Prize (DAP), The Malcolm Baldridge National Quality Award (MBNQA) and the Quality Cup (Space limitations do not allow an elaboration of these awards here). Of these three quality awards, the only one which specifically uses benchmarking as a criterion, is the MBNQA award. This award is based on criteria which allocate 1000 points to seven different major categories. Of these categories (which are to receive a total of one thousand points), ihe only category relating to benchmarking is category two. Category number two is, "Information and Analysis", and sub-category 2.2 is designated "Competitive comparisons and benchmarking". Only 20 points are allocated for this sub-category. Of the sixteen winners for the MBNQA through 1992, only Xerox has been a prominent user of benchmarking. This fact was one of the issues which set it apart from the other winners, and Xerox felt that the extensive use of benchmarking gave it an edge in many of the other categories.

It should be pointed out that winning the award does not guarantee success. Winners do look forward however, to more recognition, and winning this award has certainly opened the door to more advertising potential. As they have all found out, this alone is not sufficient in today's environment. Winners anticipate reduced costs, increased productivity, improved customer satisfaction, and higher profitability. This points out again that knowledge about one's own company, and about the industry in general, can bring rewards far greater than the awards themselves.

If benchmarking could be incorporated to a fuller extent into the awards themselves, it is felt that some essential information could be gained with very little additional expenditure. At the present time, pursuing any of the awards, and/or seeking certification, is costly and time consuming. To independently add the cost of benchmarking onto current management efforts is difficult to justify. Since the aims of both of these management tools are similar, and 
elements can be found which are common, it would seem prudent to incorporate these studies into one exercise and gain a significant edge in the information and analysis phase of the study.

In very general terms, it could be said that both benchmarking and TQM (both quality awards and certification) are types of performance indicators. As such, they add to the repertoire of tools which can be used to assess company performance. An examination of these indicators needs to be pursued.

\section{PERFORMANCE INDICATORS}

One of the issues which needs to be studied in detail and perhaps researched with an eye towards completely revamping the benchmarking model, is performance indicators. As pointed out previously, the concept has taken a different focus from old models. Probably the most significant change was the redirection of the reference point from an internal one to an external one. The indicators themselves changed, and the meaning of comparison also underwent drastic revisions.

\subsection{Current Practices}

In the pre-1970 years, benchmarking was simple and straight forward. Through the 1980's, modern philosophies and techniques have become more comprehensive, complex, and valuable. During these years, the use (or purported use) of benchmarking seemed to have increased dramatically.

On the use of benchmarking, the president of Kaiser Associates reported, "Its earliest citings were in 1979 or 1980 , but as recently as 1985 or ' 86 only half a dozen Fortune 500 companies were doing it. Now over half of them are" (Industry Week, Nov, 1990). A more recent report claims that a poll carried out by Gallup on behalf of Coopers and Lybrand found that ...two thirds of The New York Times' "Top 1000 companies" claim to use benchmarking. Over $90 \%$ of those, claim that benchmarking helps to provide new insight and that it acts as a catalyst for change. Eighty seven percent believe that benchmarking has been successful. A serious study needs to be undertaken to determine the extent of benchmarking and the type that is actually taking place. Competitive benchmarking should be emphasized.

When Xerox originated "competitive benchmarking" in 1979, they made a drastic departure from "internal benchmarking". These early results from competitive benchmarking were so startling, that a corporate vice president announced that competitive benchmarking would become a corporate-wide endeavor. The initial competitive benchmark was conducted in the manufacturing unit, then extended to a few of the operating units. At the 1983 annual shareholders meeting, the CEO announced that his number one priority was to achieve leadership through quality. Benchmarking was one of the three components of that effort. Once again, we learn from history that quality management and benchmarking are tightly interwoven, and should be modeled and researched in the same studies. The benefits have been so great, that Xerox has a program which extends their efforts in benchmarking every year. They are the inventors, the most studied, and unquestionably the experts in this area today. By this initiative, Xerox has demonstrated that an internal benchmark used to measure performance based solely on "last year's" results is of diminished value today. 
If a company wishes to begin a "benchmarking" initiative, it should begin modestly using internal markers, with a few important indicators set by management; then move aggressively into competitive benchmarking. To stay compatible with the TQM criteria, it is suggested that the functions of the enterprise should be examined and categorized as inputs to the service or product, the process itself, and all its steps, and finally the outputs. If this can be modeled for a company, or for a class of companies, then the rest of the task becomes straightforward.

An element of vital importance to TQM, is customer satisfaction. This is the element which is of high focus for this paper and which will be universal for every kind of business today and in the future. There are many elements which can be benchmarked in this area and it is receiving a great deal of attention. The customer has a strong desire to obtain "high quality" goods and services, but now the major focus is on "high value". This means that the customer wants what is perceived as high quality, but it must be available for what is perceived as a fair price.

\subsection{Integrating Ergonomics, Health and Safety}

Of all the benchmarks which receive the most neglect, ergonomics factors have to be at the top of the list. With all the interest in customer satisfaction, all the emphasis on TQM, and the profound discoveries in worker health and morale, this area deserves substantial research.

A search of the literature on benchmarking did not reveal any mention of concern for this vital element. Even in the area of TQM, its depicted role is more limited than one would expect. The role of human factors or ergonomics has primarily been that of inspector for the quality program. Some authors mention human factors for a few products such as automobile design, and furniture design, but none give extensive study to this growing area of human interaction.

If one is to consider ergonomics as a person/product interaction, ergonomics and $\mathrm{TQM} /$ benchmarking should play a role in three major areas: worker/product (service) interaction, customer-purchaser/product (service) interaction and customer-user/product (service) interaction. The last two categories must be researched separately, since they appeal to different aspects of a customer. A customer may pay money for something based on its marketing appeal. Emotional interactions, sensory appeal, sex appeal all may enter into a customer making a purchase. The other aspect of a customer then takes over and functional aspects and reliability aspects may become the more prominent concern. In each of these areas, there are opportunities for benchmarking. Improvements in many of these areas could lead to reduced costs, higher quality and greater customer satisfaction.

Looking at the first group, benchmarks could focus on one or more of the following: worker and product design interaction worker and process design interaction worker and machine compatibility worker and temperament for the job worker and quality inspectors selection/training testing 
The next two groups would have some benchmarks in common but each group would also have some unique ones. Where the buyer is concerned, he or she would have to be "excited" about quality features. The marketing specialist would then have to determine factors which would appeal to this "group" of consumers. Quality Function Deployment (QFD) could play a very powerful role in this focus. Most customers would be able to speak in terms of what they want without being encumbered with extensive technical knowledge. Possible benchmarks to be studied would be:
target group of customers
emotional interactions
marketing considerations
sensory perceptions of customers

For the customer/user, many of the above elements would be important, but functionality may begin to play a more important role. Possible benchmarks to be included would be:

functional requirements
reliability
maintenance considerations
user friendly aspects

Finally, all groups would have different needs as to the following benchmarks which would relate to human behavior:

service quality

product quality

value perception

If some of these elements could be benchmarked, this would make significant strides in TQM, could contribute to a work force of higher morale, and certainly extend customer satisfaction.

\section{SUCCESSES AND FAILURES}

There have been attempts to incorporate TQM in many firms, and many companies have made attempts at implementing benchmarking. History is replete with both successes and failures in these endeavors. In so many cases, a corporate executive lays out a strategic plan for TQM which may include an aspect of benchmarking. When the implementation phase comes, benchmarking often takes a very minor role (if any at all), and other aspects of the strategic plan receive more resources and closer attention.

It is felt that this is due, in part, to the criteria laid out for quality certification, or to the criteria laid out for winning one of the awards. Earlier it was pointed out that only one of the major awards directly uses benchmarking as a criterion, and none of the major certification programs include it. Thus, having to develop benchmarking standards, in addition to satisfying criteria for ISO 9000 , will be viewed as additional effort.

It would be well to point out that the number of companies seeking awards and/or certification has risen dramatically in the past 6 years. Since this is a fairly time consuming task, complete with serious increases in paper work as well as a significant expense to the company, it cannot 
be a casual decision. Therefore, unless a way can be found to include the benchmarking model into these undertakings, it will never reach its full potential.

Among the companies who have become very successful in incorporating benchmarking into their corporate philosophy structure are: Federal Express, American Express, L.L. Bean, General Electric, Xerox, IBM, Dow Chemical, Honda Motor, Proctor and Gamble, and Apple Computer. There have likewise been many corporations who have "tried" benchmarking as a component of their standard operating procedures and failed to make it successful. No studies could be found which documented why these companies did not find success and this study was beyond the scope of this paper. In the experience of the authors, however, the most significant cause of failure comes from "lack of management commitment" or from the concept of feeling that "if we do it, we have solved the problem and can get on with company business".

Similarities are noted when examining companies which have tried to implement TQM. Both successes and failures are available for study. An article in the October 1993 Quality Newsletter on "The Death of Quality?" described some quality bashers who rejoiced at the demise of companies who were winners of the Malcolm Baldridge award. This only reinforces the point that there is still much work to be done. These management tools are

still in their infancy and have not solved all the problems of coping with the new "world environment". They will undergo more growing pains as experience is gained and exogenous factors are better understood. For those fortunate enough to put forth the skill and determination necessary for a new corporate culture, the rewards will be great.

\section{ADVANTAGES OF BENCHMARKING AS AN ELEMENT OF TQM}

Much of the core of what is to be obtained in benchmarking can be modified to coincide directly with that needed for a TQM project. A review of the current research reveals that in one form or another, the following elements are common to both management tools:

Continuous improvement

Meeting customer requirements

Certain performance standards

Understanding industries' best practices

Concurrent engineering

Measuring of elements (targets)

Using these core elements, benchmarks could be incorporated directly into the TQM model. The real test would come in incorporating these elements into the ISO 9000 criteria. As the authors reviewed these criteria, it seems that some modest research would reveal some common, if not identical, criteria which could easily become a common core.

Currently, the biggest obstacle to overcome would be the idea of getting used to using dissimilar companies as benchmarks. Just as managers had to be educated in achieving customer satisfaction to yield a high quality product, they will need to be educated in the principles of "competitive benchmarking", and will have to be shown its benefits. 


\section{COMPETITIVE ADVANTAGES}

There are many reasons for implementing a benchmarking policy and many of the key reasons are noted in R.C. Camp's book on benchmarking. Only one reason will be noted here. This is "Becoming Competitive". This reason is sufficient to cause companies who compete on the "new world" market to take notice.

\subsection{Benchmarking Within The Organization}

Mr. Camp states that without benchmarking, a company becomes internally focused, has evolutionary change and low management commitment. With benchmarking, a company develops a concrete understanding of competition, utilizes new ideas of proven practices and technology and has a high level of commitment (Camp, p. 30). While a company will typically begin its external benchmarking by comparing companies in the same industry, much can be learned from companies of a vastly different business.

\subsection{Benchmarking Vendors}

In recent years, it has become apparent that if a company is to minimize costs, it must be concerned with all aspects of its product or service. In the past, one often neglected element was the relationship with suppliers. It is the responsibility of the vendee initially to select a supplier who meets the requirements and standards of the vendee. The ISO 9000 series has been developed to reassure purchasers that objective quality standards are being met. The ISO Standards Authority certifies that specific suppliers have achieved a minimum standard for a quality process.

\section{REFERENCES}

1. Camp R. C., Benchmarking: The Search for Industry Best Practices that Lead to Superior Performance, ASQC Quality Press, Milwaukee, Wisconsin, 1989.

2. Ishikawa, K. Guide to Quality Control, Asian Productivity Organization, Tokyo, 1993.

3. Juran, J.M: and F. Gryna, Jr. Quality Planning and Analysis, McGraw-Hill, New York, 1993.

4. "Malcolm Baldrige 1992 Award Criteria", National Institute of Standards and Technology, Gaithersburg, MD.

5. Rothery, Brian, ISO 9000, Gower Press, England, 1993

6. Tsu, Sun, The Art of War., Delacorte Press, New York, 1983 